\title{
Clinical Profile of Children with Beta-Thalassemia
}

\author{
Dilip Kumar', Aarti. A. Kinikar² \\ ${ }^{1}$ Junior Consultant, Neonatology, Ovum Women and Children Speciality Hospital, Banaswadi, Bangalore, ${ }^{2}$ Professor and Head, Department of Pediatrics, Byramjee Jee Jee \\ Bhoy Government Medical college and Sasson General Hospital, Pune, Maharashtra.
}

\section{Abstract}

Background: The pathogenesis of thalassemia is based on in effective erythropoiesis, haemolysis and a tendency to increase iron absorption, this causes monocytes and macrophages compartment hyperplasia and hyperactivity. These increased phagocytic activities reduce the capacity of phagocytic system to defend against pathogenic microorganisms. Finally, severe anemia itself is a risk factor for bacterial infections in thalassemia predominantly pneumonia. Subjects and Methods: The present study was conducted in the thalassemia unit and pediatric ward of a tertiary care, referral and teaching hospital situated in an urban area. Informed consent of parents/ caretaker of the enrolled thalassemic children were taken. Result: Among 32 patients, all except one had physical growth retardation. A thalassemic child who had recurrent infections had 11 times higher chance of having physical growth disturbance. $(\mathrm{OR}=11.12$; $\mathrm{p}$ value $=0.0066)$ compared to those who did not have recurrent infections. $59.37 \%$ of the patients who had recurrent infections had wasting and stunting, $15.62 \%$ had only wasting and $21.87 \%$ had only stunting. Conclusion: This shows that there was male predominance among the patients with infections. Out of 85 cases, $55.29 \%$ were males and $44.7 \%$ were females. Male: Female ratio was 1.236: 1.

Keywords: Beta-Thalassemia, erythropoiesis, recurrent infections.

Corresponding Author: Dr. Aarti. A. Kinikar, Professor and Head, Department of Pediatrics, Byramjee JeeJeeBhoy Government Medical college and Sasson General hospital,Pune, Maharashtra.

Received: December 2019

Accepted: December 2019

\section{Introduction}

The Thalassemias are a group of hereditary anaemias resulting from a defect in haemoglobin production. They are the world ${ }^{\text {ee }} \mathrm{s}$ most common monogenic disorders. The word "Thalassemia ${ }^{\text {ee }}$ is derived from the Greek word,,Thalassa"e meaning „sea"e. Haemoglobin disorders thought to have originated in countries where malaria was endemic. The disease was initially known to be limited to Mediterranean belt, as a result of migration of population, thalassemia, which was once confined only to the Mediterranean belt, is now found to be distributed in many parts of the world.

Although reliable data are still lacking for many regions of the world, recent data indicate that about $7 \%$ of the world population is a carrier for this haemoglobin disorder, and that 3,00,000-5, 00,000 children are born each year with the homozygous state of the disease worldwide. ${ }^{2}$ Every year approximately 10,000 to 20,000 are born with thalassemia in India. The carrier rate for thalassemia gene varies from 1-3 $\%$ in southern India to $3-15 \%$ in northern India. ${ }^{[1]}$

Infections are a frequent complication of thalassemia and they can be fatal. The morbidity and mortality rates for infections vary throughout the world depending on differences in the epidemiology of each infection and on the socio economic status of each country and also vary depending on the preventive and therapeutic strategies adopted by that country. ${ }^{[2]}$

In an Italian multicentric study, infections were the second common cause of death after heart failure in thalassemia. Similar results were reportedin Greece and in Taiwan, while in E-beta thalassemia patients in Thailand, infections were the primary cause of morbidity and mortality. The transfusion and iron chelation therapies have dramatically changed the management and prognosis of thalassemia. However, the benefits from transfusion come together with the disadvantages of the high risk of direct exposure to infection risk and indirectly to transfusion related immunomodulation. The other therapeutic options like splenectomy, nutritional deficiencies etc contribute to the infection risk. ${ }^{[3]}$

The pathogenesis of thalassemia is based on ineffective erythropoiesis, haemolysis and a tendency to increase iron absorption, this causes monocytes and macrophages compartment hyperplasia and hyperactivity. These increased phagocytic activities reduce the capacity of phagocytic system to defend against pathogenic microorganisms. Finally, severe anaemia itself is a risk factor for bacterial infections in thalassemia predominantly pneumonia. ${ }^{[4]}$

Due to frequent blood transfusions, the thalassemia patients are subjected to peroxidative stress injury by the secondary iron overload. Iron induced peroxidative damage can lead to congestive cardiac failure which is the main cause of death 
in thalassemia patient. Iron overload may also have an increased risk of developing severe infections. The best documented infection is caused by bacteria called Yersinia Enterocolitica. In thalassemia major, where there is excess iron either free or bound to desferrioxamine molecule, Yersinia grows and multiply rapidly causing serious life threatening infections. Iron overload is also related to viral infections [HIV, HBV, HCV]. ${ }^{[5]}$

\section{Subjects and Methods}

\section{Study site}

The present study was conducted in the thalassemia unit and paediatric ward of a tertiary care, referral and teaching hospital situated in an urban area.

\section{$\underline{\text { Study population }}$}

Multi transfused thalassemic children looked after in the hospital thalassemia centre.

\section{Study design}

The present study was a prospective observational study.

\section{Consent}

Informed consent of parents/ caretaker of the enrolled thalassemic children were taken.

\section{Patient selection}

Patients of thalassemia fulfilling following inclusion criteria were enrolled in the study.

\section{Inclusion criteria}

- Multi transfused thalassemic children less than 12 years of age with complaint of fever requiring admission in the pediatric ward for treatment and for blood transfusion.

- Thalassemic children admitted in other wards of the hospital with fever.

\section{Exclusion criteria}

- Patients more than 12 years of age.

- No consent from the parents / caretakers for participation.

- Patient not requiring admission and treated on OPD basis.

\section{Results}

In the present study, 85 thalassemic children were enrolled. All the enrolled children were less than 13 years of age as the hospital paediatric thalassemia unit admits children up to 12 years only.

Age at diagnosis of thalassemia in these children was as follows:

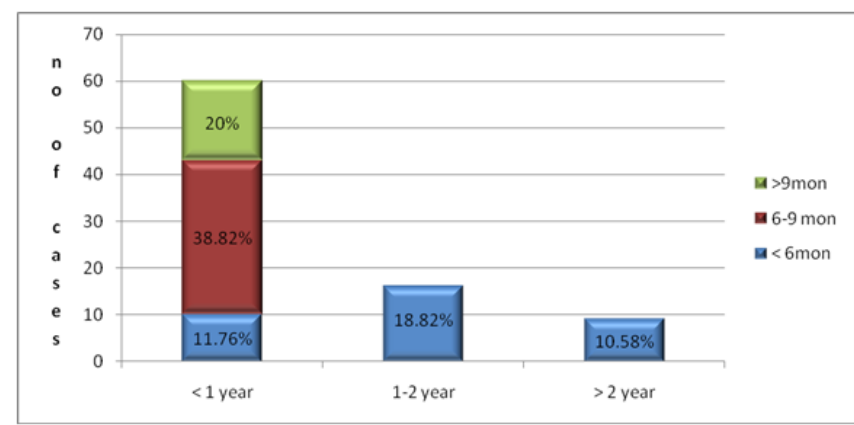

Figure 1: Age at diagnosis of thalassemia $(n=85)$

Of the 85 patients enrolled, the youngest age at which thalassemia was diagnosed was 2.5 months and the oldest age was 48 months for thalassemia major and 72 months for thalassemia inter media.

$70.58 \%$ (60 out of 85 ) of the cases were diagnosed within first year of life, out of this $38.82 \%$ (33 out of 85) were diagnosed between 6 to 9 months of age.

$18.82 \%$ (16 out of 85 ) of cases were diagnosed between 1 to 2 years and $10.58 \%$ ( 9 out of 85 ) of cases diagnosed after 2 years ofage.

Average age at diagnosis of thalassemia being 15 months, with 9 months as the medianage.

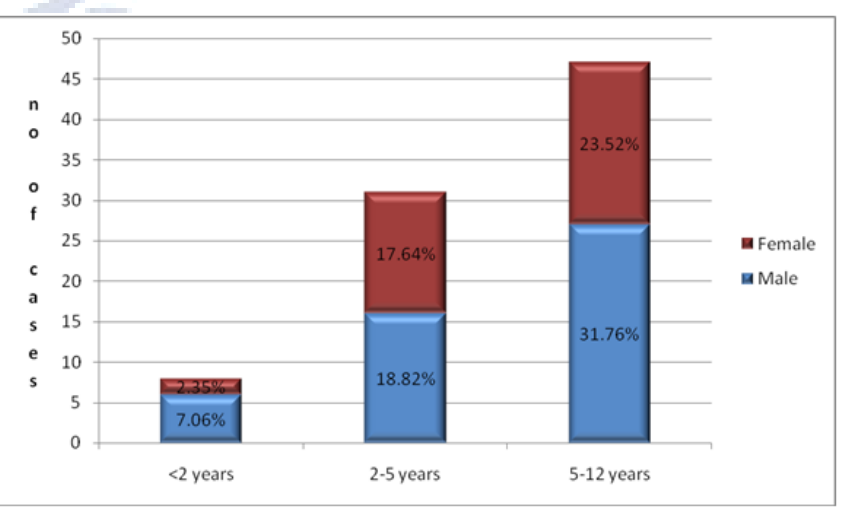

Figure 2: Age wise distribution of patients at the time of infection $(\mathbf{n}=\mathbf{8 5})$

$9.41 \%$ of the cases were below 2 years of age, $36.47 \%$ between 2-5 years and $55.29 \%$ above 5 years ofage.

The youngest of them was a 1 year old and the oldest was a 12 year old malechild.

Predominant age group affected was between 5 to 12years. From the above chart it is clear that there was male predominance in all age groups presenting withfever.

Mean (SD) age of the male patients was 6.38 years (+/- 3.1years.)

Mean (SD) age of the female patients was 6.3 years (+/- 3.1years). 


\section{Tumar \& Kinikar; Clinical Profile of Children with Beta-Thalassemia}

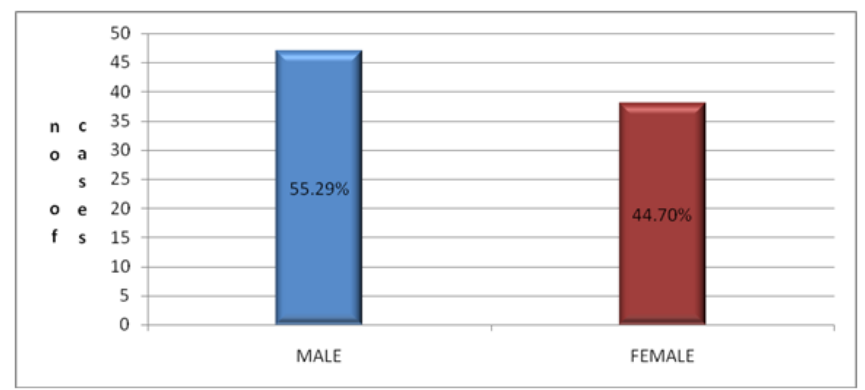

Figure 3: Sex wise distribution of the patients $(n=85)$

This shows that there was male predominance among the patients with infections.

Out of 85 cases, $55.29 \%$ were males and $44.7 \%$ werefemales.

Male: Female ratio was 1.236:1.

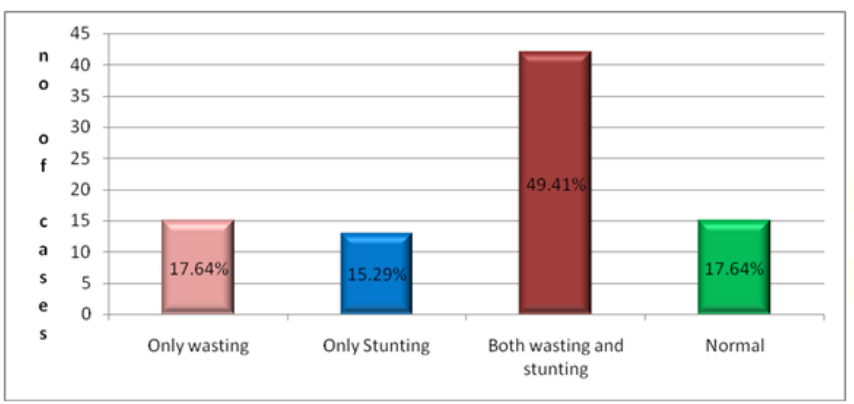

Figure 4: Distribution of patients according to growth pattern $(\mathbf{n}=\mathbf{8 5})$

Out of 85 patients studied, only $17.64 \%$ of cases had normal growth pattern.

$17.64 \%$ of patients had only wasting, $15.29 \%$ had only stunting and $49.41 \%$ had both wasting and stunting.

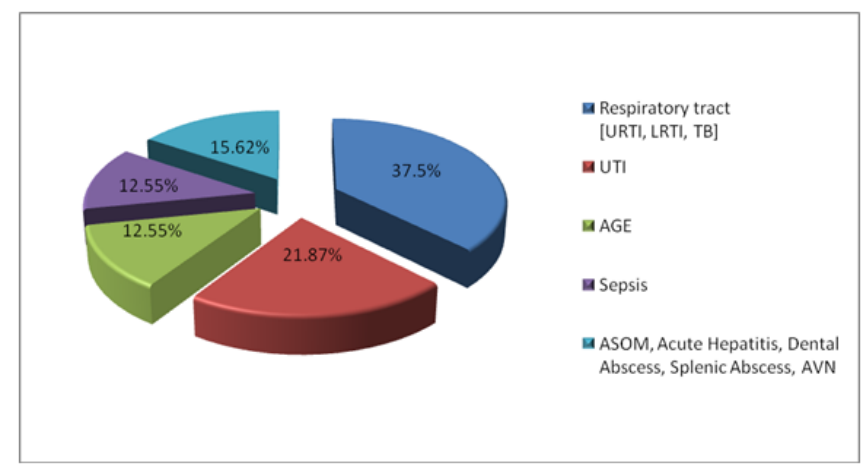

Figure 5: Representation of different systems among patients with recurrent infection

$37.5 \%$ had respiratory tract infections followed by $21.87 \%$ withUTI.

AGE and sepsis accounted to $12.55 \%$ each.
Table 1: Distribution of patients according to growth disturbance among patients with recurrent infections $(n=32)$

\begin{tabular}{|l|l|l|l|l|}
\hline & \multicolumn{2}{|l|}{ Recurrent infections } & Percentage & \multirow{2}{*}{$\begin{array}{l}\text { OR and P } \\
\text { value }\end{array}$} \\
\cline { 2 - 3 } & yes & No & & OR=11.12 \\
Wasting only & 5 & 8 & $15.62 \%$ & 0.0066 \\
\hline Stunting only & 7 & 8 & $21.87 \%$ & \\
\hline $\begin{array}{l}\text { Both wasting } \\
\text { and stunting }\end{array}$ & 19 & 23 & $59.37 \%$ & \\
\cline { 1 - 3 } Normal & 1 & 14 & $3.12 \%$ & \\
\hline Total & 32 & 53 & $100 \%$ & \\
\hline
\end{tabular}

Among 32 patients, all except one had physical growth retardation. A thalassemic child who had recurrent infections had 11 times higher chance of having physical growth disturbance. $(\mathrm{OR}=11.12 ; \mathrm{p}$ value $=0.0066)$ compared to those who did not have recurrentinfections.

$59.37 \%$ of the patients who had recurrent infections had wasting and stunting, $15.62 \%$ had only wasting and $21.87 \%$ had onlystunting.

\section{Discussion}

In our study, $70.58 \%$ of the cases were diagnosed within the first year of life; out of this $38.82 \%$ were diagnosed between 6 to 9 months of age. $18.82 \%$ cases between 1 to 2 years and $10.58 \%$ cases after 2 years of age. Average age being 15 months, at which thalassemia was diagnosed.

The mean age at diagnosis of thalassemia in our study is higher when compared to the study from Mumbai, ${ }^{[6]}$ where the mean age at diagnosis was5.5 months.

The age of diagnosis for thalassemia intermedia (only one patient) was 72 months in our study, whereas study from Mumbai stated the mean age as 51months.

The age at the time of diagnosis was higher in our study as most of our patients came from rural background where the advanced diagnostic health care facilities are not available. The difficulties in the early diagnosis encountered are the lack of awareness about the disease among the doctors working at the peripheral health care centre, lack of availability of laboratory services at the periphery.

In our country, majority of our population lives in rural area and awareness about the disease among them is very poor. Most of them bring the child to the hospital only when the child is very sick. Early diagnosis helps in early initiation of therapy, prevents repeated infections, cardiac failure anddeath. Hence, the availability of the health services and the health seeking behavior of our patients determines the age of diagnosis, which further dictates the long term outcome and survival.

In the present study $55.29 \%$ patients were above 5 years of age, $36.47 \%$ between $2-5$ years and only $9.41 \%$ are below 2 years of age at the time of presenting with infection. The average age was 6.38 years.

In a study by Taiwan et al, ${ }^{[7]}$ the mean age at diagnosis of bacterial infection was 17.5 years. This difference is mainly because no patients above 12 years were included in our 
study. Still $17.64 \%$ of our patients were more than 10 years of age.

In the past most of the children with thalassemia used to die in their infancy and early childhood because of inadequate blood transfusion, lack of appropriate chelation and improper management of the complications. But now the increased numbers of patients are seen in the adolescence and older age groups indicating that prompt transfusion regimens and modern iron chelation therapy is extending the life span of the thalassemia patients.

Nearly $55.29 \%$ in our study are males, $44.7 \%$ are females this is in contrast to studies by Hillah, Chung and Shih. Being an autosomal recessive disorder, it should be equally distributed in both sexes but higher proportion is seen in males in our study.

The underlying reasons might be the gender discrimination in the health seeking behavior for chronic illness. Generally male children are cared better and brought to hospital for illness more often in our population.

In our study, out of 85 patients with infections, $67 \%$ of the patients had wasting of which $78.37 \%$ were girls and $62.5 \%$ were boys $.64 .7 \%$ of the patients had stunting of which $68.75 \%$ were boys and $59.45 \%$ were girls .

In a multicentric study in Italy, ${ }^{[8]}$ involving 250 patients aged $10-23$ years, $37 \%$ were found to be having wasting and stunting. While in patients over 14 years of age, the percentage was $62 \%$ for males and $35 \%$ for females.

In a study at AIIMS New Delhi, ${ }^{[9]}$ various growth parameters of 233 thalassemia children were compared with 74 non thalassemic siblings, ICMR and NCHS norms. Weight and height were both found to be retarded in thalassemic children in this study.

A study by Kattamis $\mathrm{C}$ et $\mathrm{al}^{[10]}$ in 74 children with thalassemia aged 1 to 11 years, treated with three different transfusion regimens. In group 1 haemoglobin levels was maintained above $8 \mathrm{gm} \%$; in group 2 haemoglobin levels was maintained between 6-8 gm\%; in group 3, pre transfusion hemoglobin levels were below $6 \mathrm{gm} \%$.

Children in group 1 grew normally both in weight and height; those in group 2 and 3 were retarded particularly those in group 3. They concluded that frequent transfusion, in spite of their disadvantage constitutes the treatment of choice.

There are multiple factors that can cause growth retardation in our patients. One of the most important cause is anaemia itself as most of our patients were inadequately transfused which is evident from the mean pre transfusion haemoglobin levels of $5.8 \mathrm{gm} \%$ which is very much below the recommended standard of 9-10 gm\%. This severe anaemia results in chronic hypoxia to the tissues and ultimately leading to growth retardation.

The second cause for growth retardation in our patients is inadequate iron chelation leading to iron overload and multi organ damage mainly affecting liver, heart, pituitary, hypothalamus and other endocrinal organs. The mean serum ferritin levels in our study are3971.6ng/dl, which is an indication for iron chelation therapy, but $78.82 \%$ of our patients, were on irregular chelation therapy which was inadequate mainly due to non-affordability of the chelation therapy.

Because of anaemia and nutritional deficiencies thalassemia patients are more prone for repeated infection, which further adds on to the disturbance in their growth. The growth difference among those who had recurrent infections and those who did not was statistically significant $[\mathrm{OR}=11.12$ and $P$ value $=0.0066]$ in the present study.

\section{Conclusion}

- The age distribution of the patients presenting with fever $-9.41 \%$ were below 2 years of age, $36.47 \%$ were between 2-5 years and $55.29 \%$ were above 5 years of age. The youngest of them was a 1 year old and the oldest was a 12 year old male child. Predominant age group affected was between 5 to 12 years.

- Sex distribution shows slight male predominance, $55.29 \%$ males and $44.7 \%$ females.

- Majority of our patients had growth disturbance $(82.36 \%)$ in the form of only wasting (17.64\%), only stunting (15.29\%), and both wasting and stunting $(49.41 \%)$.

\section{References}

1. Weatherall DJ, Clegg JB. The Thalassemia syndromes. $4^{\text {th }}$ ed. Oxford, England: Blackwell science Ltd, 2001.

2. Weatherall DJ, Hemoglobinopathies Worldwide: Present and Future.Current Molecular Medicine 2008; 592-599.

3. Lokeshwar MR. Progress in the management of thalassemia. Indian Pediatr 2006; 43:503-506.

4. Borgna-Pignatti C, Rugolotto S, De Stefano P, et al. Survival and complications in patients with thalassemia major treated with transfusion and deferoxamine. Haematologica. 2004;89:1187-1193.

5. Ladis V, Chouliaras G, Bedousi H, et al. Longitudinal study of survival and causes of death in patients with thalassemia major in Greece. Ann N Y Acad Sci. 2005;1054:445-50.

6. Nadkarni A, Gorakshakar AC, Lu CU, Krishnamoorthy R, Ghosh K, Colah R, Mohanty D. Molecular pathogenesis and Clinical Variability of $\beta$-Thalassemia Syndromes Among Indians. Am J Hematol 2001; 68: 75-80.

7. Shih-Chung Wang, Kai-Hsin Lin, Jimmy P. S. Chern, Meng-Yao Lu, Shiann-Tarng Jou, Dong-Tsamn Lin, and Kuo-Sin Lin. (2003). Severe Bacterial Infection in Transfusion-Dependent Patients with Thalassemia Major. Clinical Infectious Disease; 37 (1October).

8. Borgna- Pignatti C, De Stefano P, Zonta et al. Growth and sexual maturation in thalassemia major. J pediatr 1985;106:150-157.

9. AniceGeorge,AparnaBhaduri,SiddharthbenandVedP.Choudhry.

10. Physical Growth parameters in thalassemic children. Indian J pediatr 1997; 64:861-871

11. Kattamis C, Touliatos N, Haidas S, and Matsonoitis N. Growth of children with Thalassemia: Effect of Different Transfusion Regimens. Arch Dis Child 1970;45:502. 
Copyright: (C) the author(s), 2019. It is an open-access article distributed under the terms of the Creative Commons Attribution License (CC BY 4.0), which permits authors to retain ownership of the copyright for their content, and allow anyone to download, reuse, reprint, modify, distribute and/or copy the content as long as the original authors and source are cited.

How to cite this article: Kumar D, Kinikar AA. Clinical Profile of Children with Beta-Thalassemia. Asian. J.Clin.Pediatr. Neonatol.2019;7(4):42-46.

DOI: dx.doi.org/10.21276/ajcpn.2019.7.4.10

Source of Support: Nil, Conflict of Interest: None declared. 